Kemp, R. B. (2007). Classifying marginalized people, focusing on natural disaster survivors. Proceedings of the North American Symposium on Knowledge Organization. Vol. 1. Available:

http://dlist.sir.arizona.edu/1908

\author{
Randall B. Kemp \\ University of Washington, Seattle, Washington, USA
}

\title{
Classifying marginalized people, focusing on natural disaster survivors
}

\begin{abstract}
The marginalization of people through classification schemes results in inadequate access to information about these people when the context is, for example, a bibliographic classification system. When the context is the classification of the people themselves, they themselves are underrepresented, for instance, by society and government support. Taking the case of the natural disaster survivor, this paper explores appropriate steps to devising an accurate classification scheme of the survivors.
\end{abstract}

A central tenet...is that at least some of the difficulties faced by persons with disabilities are not the result of functional impairments related to the disability, but rather are the result of a castification process embedded in societal institutions for rehabilitation and education and enforced by well meaning professionals. (Szymanski and Trueba, 1994, 12).

\section{Introduction}

The overarching concern of this paper is how people are marginalized through classification and knowledge organization. The questions framing this research: What classification practices, if any, marginalize people? What unintended consequences arise through well-intentioned knowledge organization practices? Within the international development arena, what classifications hinder recovery and reconstruction of lives and communities devastated by natural disaster and internal conflicts?

In examining the issue of classification and marginalized people, certain values help frame the research and ideas presented. The first is a value placed on justice for those who cannot defend themselves against other people or oppressive systems. The second important value influencing the topic selection for this paper is an emphasis on international issues. One example of international justice is the plight of natural disaster survivors.

Classification schemes wield power; how much is up for debate depending on which side you take. One way to say this is that "for any individual, group or situation, classifications and standards give advantage or they give suffering" (Bowker and Star, 1999, 6). To what extent these classifications are advantageous or producers of suffering will not be solved in this paper. The notion of advantage, however, will be used as a foil to address how people might be marginalized due to a particular classification. On the other hand, one can argue that classification is not the impetus for marginalizing people but simply an accurate reflection of how society and culture treat a certain group of people. 
Kemp, R. B. (2007). Classifying marginalized people, focusing on natural disaster survivors. Proceedings of the North American Symposium on Knowledge Organization. Vol. 1. Available:

http://dlist.sir.arizona.edu/1908

The aim of this paper is to reflect holistically on how classification and knowledge representation impacts justice and equity to marginalized people as people, rather than as concepts appearing in bodies of literature. That is, the classification of people over and above classification of items about people. Another goal is to think intentionally about how classification work, particularly within international relief and development, unintentionally marginalizes people, then offer remedial strategies.

\section{Marginalization of people through classification}

An early voice in the debate over classification practices culpable of marginalizing people was Sanford Berman. Famous, or infamous, for his lingering feuds with the Library of Congress over their subject headings, Berman criticized the labels used for certain people in the Library of Congress Subject Headings (LCSH) (Berman, 1971). Some of the headings, Berman argued, prejudiced people based on characteristics such as race, faith, ethnicity, politics, gender, sex, and age. While the dominant majority, typically those in control of LCSH, was favored with deep and fair headings, the least powerful in society were denied the same opportunity in LCSH. Rather, over-generalizations and fundamental name-calling, according to Berman, were too prevalent in LCSH for marginalized people. He went so far as to describe these negative headings as derogatory and chauvinistic. Berman was not only a critic of certain headings, he attempted to be a positive voice for change by offering suggestions on how to remedy these prejudiced headings.

The point to highlight in this brief summary of Berman's involvement with subject headings and marginalized people is to note how, in the chain of classification of marginalized people, his concerns center on information about people not the people themselves (although by association he was also speaking on behalf of the people). Berman expressed displeasure about how secondary the literature on the least powerful people was treated through vague and derogatory subject headings. In other words, access to information on these groups of people was hampered by the nature of these, to him, unfair subject headings.

Moving from LCSH to the Dewey Decimal Classification (DDC), we see the continuation and progression of concern raised over the marginalization of people by Hope Olson. Olson (1998) leverages the concept of spatial proximity to a center as a means of noting how some people groups, that is the classification of information about them, land outside the mainstream of DDC. Examples in her critique include unpaid employment as a concept widely found in women's literature but given no place in DDC. Olson's aim is to signify the difficulty of identifying the marginalization of concepts in systems of classification and offer a way to increase the boundaries around knowledge by incorporating into the dominant framework those concepts and people typically on the fringe or entirely outside the knowledge domain. Olson, writing later (Olson, 2001; Olson and Schlegl, 2001), covers, according to her, the "negative biases" in subject headings, lending additional weight to the arguments presented by Berman.

In the arena of organizational practice and the use of technology, Suchman (1994) notes that the way systems are constructed has direct bearing on enforcing or reinforcing practices and conventional order within the organization. Additionally, when these practices, and especially the people within the organization, are categorized, the interactions among people within the 
Kemp, R. B. (2007). Classifying marginalized people, focusing on natural disaster survivors. Proceedings of the North American Symposium on Knowledge Organization. Vol. 1. Available:

http://dlist.sir.arizona.edu/1908

organization are controlled to a greater degree. This classification of people within the organization affects the social order, the roles people play, and the subsequent level of authority assigned (explicitly or implicitly) to a given person. For the purposes of this paper, the important point is that how people are grouped and organized directly impacts their ability to act, including relegating some members of the organization (especially employees lower in the organization chart) to a marginal status through a combination of their job task and organizational structure.

\section{Neutrality of the classification scheme towards people}

An important point worth garnering some attention in this paper, although not a central focus for the paper, is how neutral or how powerful classification schemes really are. That is, do classification schemes neutrally reflect reality or do classification schemes actually create reality? In the case of $\mathrm{LCSH}$, perhaps it is most accurate to characterize the people responsible for its creation as enmeshed in a particular context of the dominant culture so that the perception of reality as expressed in LCSH mirrors the creators' perception of reality. They do not wield special powers to marginalize people. In the case of race and ethnicity information gathering and classification for government statistics, however, Robbin (2000) firmly believes that the classification system is not neutral and is not objective.

Within smaller organizations when the scale of the classification scheme does not attempt to organize the universal body of knowledge, the creators of the classification and ordering do possess greater influence over that smaller sphere. In the cases mentioned in Suchman (1994), the categories have politics (the title of the article, after all). That is, the categories powerfully make changes on the landscape of the organization. In this way, the classification is not neutral; it is a tool in the hands of those in power.

So, the neutrality of a given classification scheme depends largely on the intended purpose of the classification and the goals embodied in the person or group of people authoring the scheme. $\mathrm{LCSH}$, and the people responsible for its inception and updates, possess no conspiracy to marginalize. The parties responsible for DDC, likewise, are not bent on relegating women to the backwaters of knowledge representation. At worst, the authors of these classification tools are guilty of insensitivity.

The affects of these categorizations, however, it is argued here, do have severe impact on certain groups of people. A lesson to learn, then, as we move ahead, is to consider the consequences of classification on the least powerful people affected by classification. The particular case of environmental disaster survivors will be used, below, as a lens to examine this principle.

\section{Classification of tuberculosis patients}

The stories of tuberculosis (TB) patients, especially how they attempt to manage the category of their illness, provides another example of classification working to influence the perception of people. For, in their sickness, these patients embody, by the building or floor of their residence, how close they might be to the label "cured." What the doctors, nurses, and even other patients tell them about the state and change of their condition can either raise the hopes for recovery or 
Kemp, R. B. (2007). Classifying marginalized people, focusing on natural disaster survivors. Proceedings of the North American Symposium on Knowledge Organization. Vol. 1. Available:

http://dlist.sir.arizona.edu/1908

give credence to fears of a perpetual illness. ${ }^{1}$

During a time in the 19th century, TB had a romantic hold on some patients and how society viewed them. Particularly for women, the lifestyle afforded by the diagnosis led to wandering and restlessness in search of the elusive location capable of producing the most helpful climate for recovery. Such a notion would not last, however. In fact, throughout its history, TB, at least by the medical community responsible for describing and naming the disease, has been classed and reclassed to the point of recycling old labels once considered inaccurate. The overarching categories of active, inactive, or quiescent (the open negative syndrome somewhere between active and inactive) go far to place TB patients in a class that helps define who they are. Additionally, the International Classification of Diseases (ICD) includes multiple expressions of TB instead of a single entry.

TB patients are relegated to categories in a manner not conducive to static conditions. Because the patient's state changes over time in ways the categories fail to appreciate, the diagnosis and category no longer accurately represent the reality of the patient's condition. Simply, attempts to put people into static boxes of categories is in tension with the temporal and moving trajectory of that person's life (Bowker and Star, 1999). Unlike a document, such as a printed monograph, which has a static instantiation capable of being placed in a single category, say a call number in a library, the category of a person, such as a TB patient, has to take into consideration several factors constantly in flux. These factors include health, relationships, vocation, and external influences such as public laws, credit card bills, and severe weather. A person is not a static information object.

\section{Classification of environmental refugees}

Moving now to a group of people classified based on their status as environmental refugees further supports the claim that classifications of marginalized people both reflect reality and influence the quality of life of these people. Bates (2002) attempts to provide clarity and precision to a 1985 definition of environmental refugees she finds lacking. Her first tactic is to differentiate between voluntary migrants and involuntary refugees. The voluntary migrant, according to Bates, is typically a family unit moving for an anticipated economic benefit. The refugee, on the other hand, is forced to move by external factors. The distinction, Bates argues, between migrant and refugee should not be thought of as rigid and well-defined. Rather, Bates suggests these terms belong on a continuum of decision-making processes by households and communities, which "underlies the classification of environmental refugees" developed through her research (Bates, 2002, 468).

Bates' classification of environmental refugees nuances the differences among environmental disaster, environmental expropriation, and environmental deterioration. These three subcategories of environmental degradation supply the needed precision not available from the earlier definition mentioned above. Rather than explicate Bates, which is not the focus of this paper, know that she further subdivides the three types of environmental degradation categories into two further sub-categories each, resulting in six classifications of environmental refugees. ${ }^{2}$

Although the label "refugee" carries with it a certain amount of social stigma, Bates' efforts to better categorize environmental refugees in particular should not be taken as a tool from the 
Kemp, R. B. (2007). Classifying marginalized people, focusing on natural disaster survivors. Proceedings of the North American Symposium on Knowledge Organization. Vol. 1. Available:

http://dlist.sir.arizona.edu/1908

powerful to marginalize the weak in time of economic need. In this case, classification of marginalized people, which refugees are by definition, is considered a social necessity in order to alleviate the suffering of relocating due to environmental reasons. As Bates notes in her conclusion, these refined definitions of environmental refugees aid other researchers and policy makers $^{3}$ in their attempts to "prevent and relieve" peoples displaced by environmental degradation (Bates, 2002, 475).

Environmental refugee as a category is one of several in a related family of categories concerning displaced people. Terms other than the broader one of refugee include internally displaced people (IDP) and stateless people. IDPs are those people still living within their own country but no longer living in their homeland due to political, ethnic, or religious causes. Stateless people have no citizenship and no legal bond of nationality with any country. Perhaps in time the world governing bodies and researchers will add further categories to describe the as yet unknown refugees created by ongoing environmental, political, and social upheaval.

\section{Towards a classification of natural disaster survivors}

The classification of marginalized people groups is a broader research topic that finds a more narrowed focus on the particular population of environmental refugees displaced due to natural disasters. The brief outline which follows of future research goals within the context of natural disaster survivors is an attempt to begin applying the concepts of the classification of marginalized people to a tractable issue within knowledge representation.

\subsection{Information gathering on environmental refugees}

The first tactic is to gather more information about and from the refugees themselves. Crisp (2003) notes that aid agencies supposed to alleviate the suffering of refugees do not possess a full understanding of these same refugees. Consequently, research into classifying environmental refugees must begin with a thorough effort to learn more about them.

The challenges are great but must be surmounted in order to provide the most accurate classification which will in turn better inform the decision making of aid agencies. Some of the challenges to collecting information from and about environmental refugees include their wish to remain anonymous, possible threats to informants from host governments, beneficiaries of humanitarian aid telling researchers what they want to hear instead of accurate answers, access to an adequate sampling frame, validity of information gathered in often extreme conditions, retraumatizing survivors, and the safety of researchers (Jayatilaka and Muggah, 2004; Uehling, 2004).

Research must begin by devising ways to hear directly from the powerless refugees themselves, including women and children (Crisp, 2003). General and one-off surveys will not suffice as adequate information gathering tools. Advocating for "hanging out" with refugees, Rodgers (2004) is critical of the shallow information gleaned from surveys and instead argues that investing more time listening to refugees in their context will be the best research tactic. Such face to face interaction is vital according to Introna (2002) rather than mediating access to refugees through numbers, statistics, or impersonal surveys. 
Kemp, R. B. (2007). Classifying marginalized people, focusing on natural disaster survivors. Proceedings of the North American Symposium on Knowledge Organization. Vol. 1. Available:

http://dlist.sir.arizona.edu/1908

In a well-documented report covering the information needs of natural disaster survivors, several authors provide multiple cases of the 2004 tsunami survivors and their lack of information (IFRC, 2005). While this paper focuses on classifying the survivors themselves, it is important to stress the need for robust information organization schemes of information which can aid survivors in their recovery.

\subsection{Principles of a classification scheme}

The following are principles of a future classification scheme of natural disaster survivors built upon the previous step of information gathering. These principles are meant to guide the creation of a classification scheme so that natural disaster survivors are better represented in research, in the media, and in policy documents which lead to decisions related to recovery for affected people.

The first principle, after gathering deep information about natural disaster survivors, as mentioned in the previous section of the paper, is to classify natural disaster survivors with depth. Depth is achieved only after extensive research in the field. Such research will require time and effort in refugee camps as well as follow-up interviews with survivors after the recovery process has begun. Admittedly, depth is relative and subjective to some hard-to-define ideal. By mentioning depth here, rather than leaving it out on the grounds that depth is impossible, I hope to suggest accurate information gathering has a set of objective characteristics which support greater depth. Such characteristics might include the number of persons interviewed, variation in the demographic profile of interviewees, and depth of interactions as measured in the time invested with each interviewee.

A second principle for a future classification of natural disaster survivors is to classify in a humane manner. Simply put, this means not over dramatizing the situation. This principle is tightly coupled with the first. Exaggeration of the environmental situation, health issues, and lifeexpectancy might be desirable in order to receive additional relief supplies. However, falsely characterizing the situation treats the survivors as less than human by implying that only in exaggeration will the international community respond to their needs. Natural disaster survivors are in need of assistance but not at the expense of being made a caricature. They should be treated with the dignity they deserve.

Third, any classification scheme of natural disaster survivors should be constructed with improvement of life as a primary goal. ${ }^{4}$ Classifying survivors by demographics, immediate needs, available resources, and condition of shelter is a means to enhancing life on the road to recovery. Such a goal does not marginalize the survivors. Marginalizing the survivors would be simple to accomplish by forcing the survivors into permanent refugee camps or forcing them to relocate to another region in the country instead of aiding in the recovery effort in the affected area.

The fourth principle centers on improving decision making. Those in power to make decisions to support or to marginalize natural disaster survivors are one of the primary audiences of a classification scheme of natural disaster survivors. Consequently, a classification scheme that aids the decision-making process is of utmost importance. Having this as a goal does not mean the scheme should be modified in order to position the survivor in the best possible position for aid. The challenge is to construct a deep (principle 1), humane (principle 2), and 
Kemp, R. B. (2007). Classifying marginalized people, focusing on natural disaster survivors. Proceedings of the North American Symposium on Knowledge Organization. Vol. 1. Available:

http://dlist.sir.arizona.edu/1908

politically meaningful classification scheme so appropriate policies and affective immediateneed decisions emerge from a helpful scheme.

Two efforts, early in their construction, are worth mentioning, even if they are not tied to classifying the person affected by disasters but the information about disasters. The $\mathrm{W} 3 \mathrm{C}$ is in the early stages of coordinating a disaster management ontology to define a common set of core data used by the multiple actors in the disaster management arena. ${ }^{4}$ OASIS is also working on standards to increase interoperability within the emergency management community. ${ }^{5}$

\section{Conclusions}

Using TB patients and environmental refugees as cases where the classification of people impacts the power of those same people, we have evidence of the marginalizing affects of classification schemes. At times these schemes are well-intentioned yet still force people into boxes, as TB patients sometimes are. Attempting to address the unintended consequences of classification on natural disaster survivors, strategies for information gathering and principles for classification scheme building were offered. Combining accurate data gathering with a well designed schema is one possible method to empower the disadvantaged rather than marginalizing them.

Classifying natural disaster survivors into groups has the benefit of informing aid agencies which groups are in most need of assistance and the type of assistance most applicable to a given group. The structure of this classification, however, can also support marginalization of survivors when labels are inaccurately assigned or the classification scheme of people is poorly designed in the first place. Thus, the scheme adversely shapes the lives of the survivors when it is designed without careful attention to realities of living in a post-disaster context.

Of course, the above discussion begs the question of purpose. Why classify disaster survivors at all? I have commented that knowing who the survivors are on some classification scale allows those agencies and parties responsible for providing assistance an added level of information with which to make decisions. If all survivors are lumped into one category, "survivor," then the subsequent aid is less likely to make the necessary positive impact.

It is hoped that this discussion about classifying natural survivors contributes to the information organization practices of relief agencies such that the agencies are better aware of the characteristics of the survivors in order to respect the humanity of the survivor and provide pertinent assistance for a healthy recovery.

\section{Notes}

1. In another context related to the health of the body, Shakespeare (1994) finds that cultural representation of disabled persons prejudices them. He also draws parallels to feminist works noting how women are sometimes thought of as "other," as are disabled people.

2. See Bates $(2002,470)$ for a helpful table with these six categories.

3. Writing the same year as Bates, Myers (2002) claimed a continued problem with the lack of official recognition of environmental refugees.

4. I am reminded of Olson (1999) and her claim that classification schemes are created with 
Kemp, R. B. (2007). Classifying marginalized people, focusing on natural disaster survivors. Proceedings of the North American Symposium on Knowledge Organization. Vol. 1. Available:

http://dlist.sir.arizona.edu/1908

some goal (teleology) in mind, which leads to a cultural classification not a universal classification.

5. http://esw.w3.org/topic/DisasterManagement

6. http://www.oasis-open.org/committees/tc home.php?\%20wg abbrev=emergency

\section{References}

Bates, D. C. (2002). Environmental refugees? Classifying human migrations caused by environmental change. Population and Environment, 23(5):465-477.

Berman, S. (1971). Prejudices and antipathies: A tract on the LC subject heads concerning people. Scarecrow Press, Metuchen: NJ.

Bowker, G. C. and Star, S. L. (1999). Sorting things out: Classification and its consequences. MIT Press, Cambridge: MA.

Crisp, J. (2003). Why do we know so little about refugees? How can we learn more? Forced Migration Review, 18:55.

IFRC (2005). World disasters report 2005: Focus on information in disasters. Kumarian Press, Bloomfield, CT.

Introna, L. D. (2002). The (im)possibility of ethics in the information age. Information and Organization, 12:71-84.

Jayatilaka, D. and Muggah, R. (2004). Where there is no information: IDP vulnerability assessments in Sri Lanka's borderlands. Forced Migration Review, 20:39-41.

Myers, N. (2002). Environmental refugees: A growing phenomenon of the 21 st century. Philosophical Transactions: Biological Sciences, 357(1420):609-613.

Olson, H. A. (1998). Mapping beyond Dewey's boundaries: constructing classificatory space for marginalized knowledge domains. Library Trends, 47(2):233-254.

Olson, H. A. (1999). Exclusivity, teleology and hierarchy: Our Aristotelean legacy. Knowledge Organization, 26(2):65-73.

Olson, H. A. (2001). The power to name: Representation in library catalogs. Signs, 26(3):639-668.

Olson, H. A. and Schlegl, R. (2001). Standardization, objectivity, and user focus: A meta-analysis of subject access critiques. Cataloging \& Classification Quarterly, 32(2):61-80.

Robbin, A. (2000). Classifying racial and ethnic group data in the United States: The politics of negotiation and accommodation. Journal of Government Information, 27:129-156.

Rodgers, G. (2004). 'Hanging out' with forced migrants: Methodological and ethical challenges. Forced Migration Review, 21:48-49.

Shakespeare, T. (1994). Cultural representation of disable people: Dustbins for disavowal? Disability \& Society, 9(3):283-299.

Suchman, L. (1994). Do categories have politics? The language/action perspective reconsidered. Computer Supported Cooperative Work, 2:177-190.

Szymanski, E. M. and Trueba, H. T. (1994). Castification of people with disabilities: Potential disempowering aspects of classification in disability services. The Journal of Rehabilitation, 60(3):12-20.

Uehling, G. (2004). How can we obtain the information we need about refugees? Forced Migration Review, 20:48. 